\title{
Aplicação dos Princípios Analítico-Comportamentais para Alterar o Comportamento de uma Esquizofrênica
}

\author{
Elaine Miranda \\ Universidade Paulista \\ Ilma A Goulart de Souza Britto ${ }^{1}$ \\ Pontificia Universidade Católica de Goiás
}

\begin{abstract}
Resumo - O presente estudo investigou o comportamento de uma esquizofrênica crônica via princípios da análise do comportamento. A participante era do sexo feminino, 57 anos, solteira e com histórico de várias internações desde os 18 anos de idade. As classes de comportamentos-problema que sofreram intervenção: contato olho a olho, isolar-se no pátio, participar dos eventos da instituição, etc. Para o controle dos procedimentos foi utilizado o delineamento de reversão do tipo ABAB, seguido de follow-up. O delineamento foi iniciado com a fase de linha de base I. Nas fases de intervenções I e II foram utilizados procedimentos de reforçamento positivo, modelagem e extinção. Os resultados demonstraram que os procedimentos da análise do comportamento foram efetivos para controlar os comportamentos-problema apresentados pela participante.
\end{abstract}

Palavras chaves: esquizofrenia; análise funcional; intervenção comportamental.

\section{Application of the Principles of Behavior Analysis to Change the Behavior of a Chronic Schizophrenic}

\begin{abstract}
The present study investigated the behavior of a chronic schizophrenic using the principles of behavior analysis. The participant was female, age 57, single and has had multiple hospitalizations since the age of 18 . The types of problematic behavior that received intervention were: eye contact, self isolation in the yard, participation in the events of the institution, and others. To control the effect of the intervention procedures the ABAB reversal design followed by a follow-up was used. The experiment started with the baseline of phase I. In intervention phases I and II positive reinforcement, modeling and extinction procedures were used. The results indicated that the procedures of behavior analysis were effective to control the problematic-behavior displayed by the participant.
\end{abstract}

Keywords: schizophrenia; functional analysis; behavior intervention

A investigação do comportamento do esquizofrênico como dado de pesquisa ampliou a aplicação da ciência do comportamento para a compreensão da esquizofrenia. Como exemplo, as pesquisas realizadas entre 1953 e 1965 por B. F. Skinner e O. Lindsley nas quais foram utilizados os princípios da análise experimental do comportamento com pacientes psiquiátricos no Hospital Metropolitano em Waltham, Massachusetts. Essas pesquisas desempenharam um papel fundamental na história e extensão das estratégias operantes ao abrir uma importante área do comportamento a uma abordagem científica para investigar classes comportamentais de pacientes institucionalizados com o diagnóstico de esquizofrenia. Também promoveram uma aplicação piloto das estratégias operantes para o estudo psicofarmacológico, trazendo assim, inovações metodológicas que se contextualizaram como referência para a revolução psicofarmacológica naquela década (Rutherford, 2003; Sidman, 2005).

Ainda, com efeito, as pesquisas demonstraram que o comportamento de alguns esquizofrênicos foi fortalecido com dinheiro, o de outros com cigarros, doces, dentre outros reforçadores arbitrários. Dessa forma, ao manipular o refor-

1 Endereço para correspondência: Rua Asphília, Quadra A3 Lote 20, Residencial dos Ipês, AlphaVille Flamboyant, Goiânia. GO. CEP: 74884-547. Fone: (62) 9979-0708. ço, foi possível estudar comportamentos diferentes como o altruísmo - puxar uma alavanca e produzir leite para um gato faminto - ou o interesse homo e heterossexual - nus artísticos como reforçadores. Foi verificado também que sessões terapêuticas com uma estudante de enfermagem foram seis vezes mais efetivas do que $100 \mathrm{mg}$ de iproniazide para conseguir que um esquizofrênico crônico respondesse (Reese, 1966/1978; Rutherford, 2003; Staats \& Staats, 1963/1973).

Replicações sistemáticas dessas pesquisas realizadas por Ayllon e Haughton (1964) Ayllon e Michael (1964), Ayllon e Azrin, (1968) demonstraram que procedimentos relativamente simples produziram resultados bem sucedidos, ou seja, os pesquisadores tiveram êxitos na modificação de vários tipos de comportamentos problema emitidos por esquizofrênicos.

Já Isaacs, Thomas e Goldiamond (1964) reinstalaram o comportamento verbal no repertório de um paciente esquizofrênico catatônico institucionalizado que se mostrava mudo durante dezenove anos. O experimento teve como objetivo a aplicação de um programa de modelagem com o uso de chiclete como um estímulo discriminativo. Inicialmente, os pesquisadores sentiram dificuldade em encontrar um estímulo reforçador adequado para ele - nem mesmo o cigarro, que fora aceito por outros membros, fora eficaz. Acidentalmente, o experimentador deixou cair um pacote de chicletes no chão, e percebeu que os olhos do paciente se direcionaram ao 
chiclete. Nas primeiras semanas, o chiclete era segurado em frente ao rosto do pesquisador e a resposta de olhar em direção a ele era reforçada. Progressivamente, o experimentador exigia movimentos dos olhos e lábios para serem reforçados. Desse modo, uma relação entre o chiclete, movimentos de olhos e lábios e a obtenção do chiclete foi estabelecida. Em seguida, na quinta e sexta semana, o experimentador segurava o chiclete e dizia "gum, gum" e falas aproximadas a essa eram reforçadas. Finalmente, na sexta semana o paciente chegou a dizer espontaneamente "Gum, please" (Chiclete, por favor) e também já era capaz de responder questões acerca de seu nome e idade.

O estudo realizado por Lidz, Cornelison, Terry e Fleck (1958 conforme citado por Staats \& Staats, 1963/1973) fez referências ao fato de dois irmãos esquizofrênicos acreditarem que "discordância" significava prisão de ventre. Sendo analisadas histórias de aprendizagem de ambos, verificou-se que sempre que os filhos discordavam da mãe, a mesma lhes dizia que estavam com prisão de ventre e lhes dava um clister. O procedimento utilizado condicionou um significado fora do comum à palavra "discordância", envolvendo o controle de estímulo inadequado na aprendizagem de comportamentos extremos. Esse estudo ofereceu evidências que ilusões, sentimentos de grandiosidade, negação dos indícios da realidade e outras formas de comportamentos característicos dos esquizofrênicos são aprendidas.

Nos últimos anos, houve um aumento dos estudos que abordaram o comportamento verbal delirante ou inapropriado de indivíduos com o diagnóstico de esquizofrenia também por meio de procedimentos de avaliação experimental. Especificamente, classes verbais inapropriadas foram avaliadas com o uso de uma metodologia de análise funcional em delineamentos de múltiplas condições: atenção, demanda, controle e sozinho (Britto, Rodrigues, Alves \& Quinta, 2010; DeLeon, Arnold, Rodriguez-Catter \& Uy 2003; Dixon, Benedict \& Larson, 2001; Lancaster et al., 2004; Marcon; 2010; Santana, 2008; Wilder, Masuda O'Connor \& Bahan, 2001). Os resultados desses estudos demonstraram uma alta taxa das classes verbais inapropriadas durante as condições de atenção e demanda; baixa taxa nas condições de controle e não ocorrências nas condições de sozinho.

Britto, Rodrigues, Santos e Ribeiro (2006) utilizaram os princípios da análise do comportamento para alterar as verbalizações inapropriadas de um esquizofrênico de 49 anos, com histórico de internações desde os 19 anos de idade. Os resultados demonstraram as alterações das falas inapropriadas do participante, via procedimentos de reforçamento diferencial de comportamentos alternativos juntamente com a extinção, bem como mudanças no modo de comportar-se em relação às demandas de seu ambiente social.

Vollmer, Borrero, Wright, Camp e Lalli (2001) sugerem que ao identificar contingências de reforço em uma avaliação funcional, informações úteis sobre a natureza de um comportamento problema são obtidas e, ao mesmo tempo, uma ligação entre avaliação e tratamento deve ser planejado. Se uma análise funcional mostra que os comportamentos desorganizados do esquizofrênico são reforçados pela atenção social, então a extinção para os desorganizados e o reforço social para os desejados deve compor o tratamento (Britto et al., 2006; DeLeon et al., 2003; Dixon et al., 2001; Santana,
2008; Wilder et al., 2001). Em outras palavras, as informações obtidas a partir da avaliação funcional podem ser utilizadas para determinar qual reforçador deve ser suspenso na sequência de ocorrências do comportamento problema e que reforçador deve ser disponibilizado como uma consequência para o comportamento desejado.

\section{Sobre o comportamento do esquizofrênico}

A Associação Americana de Psiquiatria por meio do Manual Diagnóstico e Estatístico dos Transtornos Mentais, o DSM-IV-TR (APA, 2000/2002), define a esquizofrenia como um transtorno psicótico cuja remissão dos sintomas não é comum. Os sintomas positivos incluem exageros do raciocínio lógico e da percepção, da linguagem, da comunicação e do controle comportamental. Já os sintomas negativos são definidos pela restrição da expressão emocional, da fluência do pensamento e da iniciação de comportamentos dirigidos a um objetivo.

$\mathrm{Na}$ verdade, nota-se que o indivíduo esquizofrênico opera em seu ambiente de modo desorganizado. E o comportamento desorganizado assume papel primário em vez de secundário, uma vez que o esquizofrênico recebe o diagnóstico também pelo que fala. Ora fala de modo estranho, incompreensível, incoerente ou falso (delírios), ora se comporta como se visse ou ouvisse estímulos que não estão presentes (alucinações). Para desvendar o que significa essa atividade, Skinner (1953/1970) introduziu o conceito de visão condicionada: ver na ausência do objeto. A sensação de ver sem o objeto é uma resposta sensorial aprendida que ocorre por meio do condicionamento clássico. E essa sensação aprendida que ocorre na ausência de um estímulo pode ser nomeada de imagem ou alucinação (Britto, 2004; Staats, 1996).

De acordo com Martin e Pear (2007/2009), a resposta sensorial de ver ou ouvir na ausência de estímulos constitui um tipo de pensamento e grande parte de nosso pensamento é comportamento verbal. Se você fechar os olhos e pensar em um céu azul com nuvens brancas, as palavras eliciam atividades na parte visual do cérebro, de forma que você tem a sensação de 'ver' a cena real. Os autores citam o exemplo: um jovem vivencia encontros sexuais intensos com uma parceira que usava um perfume característico. Depois, certo dia em uma loja, alguém usa o mesmo perfume. O jovem imaginou ver a parceira (visão condicionada), sentiu formigamento em partes do corpo (sentimento condicionado) e até imaginou ouvir a voz da parceira (audição condicionada).

Ver, sentir ou ouvir necessariamente não exigirá a presença de estímulos públicos. As ações internas que ocorrem quando estamos pensando são reais: vemos, sentimos ou ouvimos enquanto respondemos às palavras, estímulos visuais e auditivos que adquiriram funções sensoriais por meio do condicionamento clássico (Britto, 2004; Burns, Heiby \& Tharp, 1983; Martin \& Pear, 2007/2009; Skinner, 1953/1970; Staats, 1996). Pode-se afirmar, então, que o esquizofrênico aprendeu a responder discriminativamente, de modo verbal, às suas próprias sensações, ao seu próprio pensamento. Portanto, a voz que o esquizofrênico diz ouvir é o seu próprio pensamento e não vozes de outras pessoas. 
Segundo Skinner (1973/1979), o comportamento psicótico é parte e parcela do comportamento humano e o que é chamado na literatura de sintoma deve ser compreendido como comportamento e como tal deve ser analisado. Skinner (1969) afirma também que o comportamento do esquizofrênico é problema, simplesmente porque não é característico da situação; o problema não consiste em achar na estrutura do comportamento observado algum indício de como fazê-lo desaparecer, mas, antes, em exigir o comportamento que está faltando. Assim sendo, os analistas do comportamento têm procurado responder questões complexas sobre o porquê de esquizofrênicos se comportarem da maneira como o fazem.

O objetivo do presente estudo foi investigar o comportamento de uma pessoa institucionalizada e diagnosticada como esquizofrênica crônica e retardo mental. Optou-se por utilizar o delineamento de reversão-replicação $\mathrm{ABAB}$ seguido por follow-up. O programa de intervenção foi conduzido em duas classes de respostas: aumentar os comportamentos desejados e diminuir os comportamentos indesejados. Com a intervenção pretendeu-se facilitar a interação da participante no seu meio social.

\section{Método}

\section{Participante}

Participou uma pessoa do sexo feminino, 57 anos, solteira, semi-analfabeta, com dois diagnósticos psiquiátricos: esquizofrenia crônica e transtorno mental. Residia em uma instituição psiquiátrica há mais de trinta anos. A participante foi estuprada aos 18 anos de idade e, desde então, apresentou comportamentos desorganizados que justificaram sua internação em várias instituições psiquiátricas. Durante a fase de coleta de dados, fazia uso diário dos seguintes medicamentos: fenitoína $100 \mathrm{mg}$; clonazepan $20 \mathrm{mg}$; haloperidol, $5 \mathrm{mg}$; cloridrato de clorpromazina $100 \mathrm{mg}$; flunitrazepam $1 \mathrm{mg}$; polivitamínico (buclizina + cafeína + lisina + complexo B) $1 \mathrm{~g}$. E, também, de uma ampola de cloridato de flufenazina $1 \mathrm{ml}$, que lhe era administrado via intramuscular.

\section{Ambiente e Materiais}

O estudo foi desenvolvido numa instituição particular do município de Goiânia em parceria com o Sistema Único de Saúde (SUS). A instituição se propunha a atender pessoas portadoras de transtorno mental em suas dependências. A instituição possuía uma equipe de profissionais formada por médicos psiquiatras, psicólogo, terapeuta ocupacional, técnicas de enfermagem, dentre outros.

Os materiais utilizados nas sessões foram: uma prancheta; uma câmera filmadora VHS; uma fita de vídeo VHS; estojo de doze lápis de giz de cera; copos, pratos e colheres de plástico descartáveis; um par de sandálias havaianas; comestíveis (pamonha de sal, bolo de cenoura, queijo minas, pães de queijo, mortadela de frango, requeijão, biscoito de polvilho, abacates, bombons e balas diversas); agasalho; batom; esmalte e Folhas de Registro.

\section{Procedimento}

Foi encaminhado um documento para ser lido e, por meio deste, obter a autorização para o início dos procedimentos. Assim, foi obtido o Termo de Aprovação pelo Comitê de Ética da instituição. A instituição foi informada que o material obtido por meio da pesquisa seria objeto da presente investigação, bem como seus resultados publicados em periódicos, congressos, revistas etc.

Entrevista para avaliação funcional foi realizada com três membros da equipe de enfermagem com a finalidade de identificar as rotinas associadas com os comportamentos-problema da participante, suas atividades, horários ou locais onde os comportamentos tinham maior probabilidade de ocorrer. A entrevista para avaliação funcional foi traduzida e adaptada de O’Neill et al., (1997). As sessões de observações diretas foram iniciadas em lugares e momentos distintos por meio de registro em vídeo. O material registrado em vídeo proporcionou importantes informações como, por exemplo, os registros dos comportamentos problema, suas durações e as funções observadas. Vários comportamentos-problemas foram observados, entre eles, dar tapas, ameaçar ou empurrar o outro. Essa classe de comportamentos ocorreu quando uma ordem de uma pessoa da equipe de enfermagem foi feita para que ela se dirigisse à sala de recreação. A função era a de fugir/escapar da ordem da auxiliar de enfermagem.

A participante apresentava comportamentos incomuns, dentre eles: se afastava das demais pessoas no pátio, se recusava a participar de qualquer atividade indicada pelos profissionais da instituição, ou desviava o olhar das pessoas tanto do sexo masculino como feminino. Além disso, permanecia grande parte do dia deitada no leito ou assentada num banco no pátio, mantendo-se sempre isolada dos demais internos. Urinava e defecava no pátio. Agressões a funcionários e pacientes eram frequentes. Dormia sozinha em seu quarto, por precaução, para não agredir outros pacientes. Mantinha um velho cobertor enrolado na cabeça. Bebia água do vaso sanitário ou da torneira do banheiro sem uso de qualquer vasilhame - copo, caneca -, mesmo porque não possuía, e nem buscava um copo para ser utilizado quando ia beber água.

Foi apresentada a participante uma lista de comestíveis para a identificação dos potenciais reforçadores, tais como: pão de queijo, bolo de cenoura, requeijão, pamonha, mortadela de frango, abacate, queijo minas, etc. Eram anotados em uma folha de registro, os nomes dos itens escolhidos pela participante além de oportunizar solicitação de algo mais. Assim, tornou-se possível estabelecer um escalonamento hierárquico entre os diversos reforçadores utilizados. As sessões foram realizadas três vezes por semana nos períodos matutinos e vespertinos durante quatro meses consecutivos. A duração das sessões variou de trinta a quarenta minutos.

O delineamento de reversão-replicação no formato $\mathrm{ABAB}$, seguido de follow-up foi utilizado para demonstrar controle experimental dos procedimentos. Cada comportamento da participante era observado e os dados de Linha de Base (LB-I) foram coletados em quatro sessões para cada comportamento. Após a Linha de Base (LB-I), foi iniciada a Intervenção I (INT-I) que durou seis sessões para cada comportamento. A seguir houve um retorno à fase de Linha de Base (LB-II) com quatro sessões, que foi seguida nova- 
mente por um período de Intervenção II (INT-II) que durou seis sessões. Após o delineamento de reversão-replicação ser completado para o primeiro comportamento, repetiu-se o delineamento para o segundo e assim sucessivamente. Após transcorrer um mês sem contato com a participante foi realizado o follow-up.

O programa de intervenção foi programado para diminuir os excessos comportamentais da participante como agredir as pessoas com tapas e aumentar comportamentos desejados, por exemplo, manter contato olho a olho com as pessoas. A Tabela 1 apresenta a lista dos comportamentos que sofreram intervenção, as fases do delineamento de reversão-replicação e a quantidade de sessões.

\section{Dar tapas, ameaçar e empurrar pessoas.}

Quando da aproximação de pessoas com um pedido, embora cabisbaixa e olhando de modo oblíquo, a participante levantava o braço direito ou esquerdo, dependendo de sua posição, estendia a mão e batia na pessoa, empurrando-a. Enquanto forçava esse contato falava com certo padrão sonoro ao franzir as sobrancelhas: "Sai daqui, vou furar seu olho ou vou matar você". O enfraquecimento dessa classe permitiria que as outras pessoas se aproximassem e conversasse com a participante e ao mesmo tempo o comportamento de agredir poderia se tornar irrelevante.

\section{Linha de base I e linha de base II.}

A pesquisadora aproximava-se da participante no pátio e conversava com a mesma por aproximadamente 5 minutos. Em seguida convidava pessoas de ambos os sexos para se aproximarem da participante e com ela conversarem. A pesquisadora falou: "Vou chamar alguém para conversar com nós duas, ok?'. Se a participante emitisse as respostas agressivas, num tempo de 40 minutos, as respostas (dar tapas, empurrar ou fazer ameaças) eram anotadas na folha de registro.

\section{Intervenção I e intervenção II: Reforçamento positivo e extinção.}

Nas sessões de Intervenção I, a pesquisadora após ter interagido com a participante durante 5 minutos no pátio, convidou algumas pessoas para se aproximarem e conversarem com a participante. A pesquisadora falou: "Vou chamar alguém para conversar com nós duas, ok?". Se a participante conversasse com as pessoas, essa resposta era reforçada. Se durante a interação ocorressem tapas, empurrões ou quaisquer das verbalizações: "Sai daqui, vou furar seus olhos ou vou matar você", a pesquisadora imediatamente ignorava a participante e dirigia sua atenção para outra pessoa ao tempo em que lhe dava as costas, por um período de um a dois minutos e só retornava sua atenção para a participante após ter transcorrido esse tempo.

\section{Manter contato olho a olho.}

Quando do contato com outras pessoas a participante desviava o olhar e fugia do contato visual. O contato olho a olho foi definido como olhar direcionado a outra pessoa na metade superior do seu rosto, por segundos. As sessões para o comportamento de olhar nos olhos foram realizadas no quarto da participante e no pátio.

\section{Linha de base I e linha de base II.}

As sessões da Linha de Base I para o comportamento de olhar nos olhos tiveram início quando a pesquisadora instruiu a participante: "Olhe dentro dos meus olhos!". Se a

Tabela 1. Fases do delineamento de reversão-replicação e follow-up de uma participante com o diagnóstico de esquizofrenia.

\begin{tabular}{|c|c|c|c|c|c|}
\hline Comportamentos que sofreram intervenção & $\begin{array}{c}\text { Fase de } \\
\text { LB - I }\end{array}$ & $\begin{array}{l}\text { Fase de } \\
\text { INT - I }\end{array}$ & $\begin{array}{l}\text { Fase de } \\
\text { LB - II }\end{array}$ & $\begin{array}{l}\text { Fase de } \\
\text { INT - II }\end{array}$ & Follow-up \\
\hline Dar tapas, ameaçar e empurrar as pessoas & 4 & 6 & 4 & 6 & 2 \\
\hline Manter contato olho a olho & 4 & 6 & 4 & 6 & 2 \\
\hline Ficar sozinha, sem atenção & 4 & 6 & 4 & 6 & 2 \\
\hline Recusar participar de tarefas e eventos & 4 & 6 & 4 & 6 & 2 \\
\hline Executar uma atividade durante tempo livre & 4 & 6 & 4 & 6 & 2 \\
\hline Beber água no copo & 4 & 6 & 4 & 6 & 2 \\
\hline Bater palmas & 4 & 6 & 4 & 6 & 2 \\
\hline
\end{tabular}


participante olhasse para a pesquisadora, seu comportamento era registrado.

\section{Intervenção I e intervenção II: Modelagem e reforçamento positivo.}

Nestas fases a pesquisadora falou para a participante: "Olhe dentro dos meus olhos!" e para modelar esse comportamento a pesquisadora reforçava qualquer movimento dos olhos. Após ter estabelecido esta relação, a pesquisadora suspendeu os reforçadores até que a participante olhasse dentro de seus olhos. Progressivamente, a pesquisadora foi conduzindo a participante a manter contato olho a olho com outras pessoas. Sempre era indicada uma nova pessoa e assim foram exigidos contatos visuais com internos, pessoal da enfermagem ou funcionários da instituição de ambos os sexos. Ao disponibilizar os reforçadores a pesquisadora chamava a participante pelo nome, olhava dentro de seus olhos, sorria e em seguida reforçava o seu comportamento. Na intervenção I os reforçadores foram utilizados os comestíveis e a atenção social; na intervenção II foi utilizada apenas atenção social como reforço. A duração das sessões foi 30 minutos.

\section{Ficar sozinha, sem atenção.}

Esta classe foi definida pela topografia comportamental apresentada pela participante que caracterizava ausência de movimentos: a participante permanecia cabisbaixa, isolada, enrolada no cobertor, sentada num banco do pátio ou deitada num leito, por horas fugindo das demais pessoas. $\mathrm{O}$ aproximar-se de uma pessoa foi definida como falas espontâneas, perguntas ou comentários feitos pela participante a outras pessoas.

\section{Linha de base I e linha de base II.}

A pesquisadora instruiu a participante a se aproximar de uma pessoa e conversar com ela: "Quero que você se aproxime dela e lhe diga: Bom dia!“. Se a participante se aproximasse e falasse com a pessoa indicada, mesmo por alguns minutos, o número de intervalos em que ocorria a resposta era anotado na folha de registro.

\section{Intervenção I e intervenção II: Modelagem e reforçamento positivo.}

Na primeira sessão da fase de Intervenção I, a pesquisadora pedia à participante para aproximar-se de alguém indicado pela mesma com quem deveria conversar um pouco. A pesquisadora dizia à participante: "Quero que você se aproxime dela e lhe diga: Bom dia!". Se a participante olhasse para a pessoa este comportamento era reforçado. Após ter estabelecido esta relação, a pesquisadora suspendia o reforço até que ocorresse outro movimento da participante em relação à pessoa indicada. Desse modo, uma relação foi estabelecida entre os movimentos da participante e a obtenção de comestíveis. A pesquisadora suspendeu os reforçadores até que a participante emitisse algum som vocal com uma pessoa indicada. Com o estabelecimento desta estratégia, a pesquisadora reforçou as aproximações e vocalizações da participante até que ela prolongasse as conversações. A pesquisadora progressivamente exigia um comportamento da mesma classe. Se a participante realizasse a tarefa, seu comportamento era reforçado e tinha sua resposta registrada.

\section{Recusar a participar das tarefas ou eventos.}

A participante era deixada no quarto, deitada no leito por um longo período do dia, enrolada no cobertor. Mantinha-se distante do grupo e não se orientava para execução de atividades promovidas pela instituição: atividade física (caminhadas, alongamento), assistir televisão, dançar, fazer trabalhos manuais (colagem, pinturas, cartões), folhear revistas ou participar de qualquer atividade ali desenvolvida.

\section{Linha de base I e linha de base II.}

A pesquisadora dava instruções para a participante se aproximar do grupo que geralmente se reunia no centro de recreação: "Quero que você se aproxime daquele grupo" (a mestranda apontava em direção ao grupo), "Observe o que eles estão fazendo e permaneça junto a eles por 2 minutos". Se a participante emitisse um dos dois comportamentos, sua resposta apenas registrada.

\section{Intervenção I e intervenção II: Modelagem e sinal de aprovação.}

Nas primeiras sessões da Intervenção I, a participante era convidada pela pesquisadora a sair do leito e assentar-se no banco do pátio, próximo do centro de recreação, onde se encontrava o grupo. Enquanto ela estivesse levantando-se da cama e indo em direção à porta, era imediatamente reforçada. Progressivamente, a pesquisadora reforçava os comportamentos da mesma classe. A emissão do comportamento de se aproximar e permanecer junto ao grupo durante as atividades foi registrado e reforçado com o Sinal de Aprovação emitido pela pesquisadora. As sessões para o comportamento de aproximar-se das pessoas em alguma atividade tiveram a duração de 30 minutos.

\section{Executar uma atividade durante o tempo livre.}

Foram selecionadas as atividades de desenho livre. O desenho livre consistia em a participante pegar os lápis de cor e fazer quaisquer riscos numa folha de papel em branco. A participante escolhia a cor e pegava com a mão direita o lápis, levava em direção à folha de papel e iniciava a atividade. $\mathrm{O}$ comportamento era considerado findado quando a mesma realizava vários desenhos no período de 30 minutos - tempo de duração da sessão. Tais comportamentos tinham a função 
de estimular o comportamento da participante a emitir a nova atividade na presença do reforço fornecido pela pesquisadora.

\section{Linha de base I e linha de base II.}

A pesquisadora aproximava-se da participante com o material de desenho (prancheta, folhas de papel e um estojo contendo 12 lápis de giz de cera coloridos) e solicitava à mesma que desenhasse algo que poderia ser uma casa, uma flor ou qualquer coisa de sua preferência.

\section{Intervenção I e intervenção I: Reforçamento positivo e extinção.}

Nas fases de Intervenção I e II a participante era solicitada a riscar o papel em branco com uma cor de sua preferência. Era colocado à sua frente o estojo aberto com os lápis de cera e folhas de papel em branco. Se a participante realizasse a atividade, a pesquisadora registrava os intervalos, a partir do contato direto com os lápis de cera no papel até o final da atividade. $\mathrm{O}$ comportamento de desenhar foi reforçado com a atenção social. Se a participante emitisse qualquer outro comportamento, a pesquisadora se afastava dela por um período de até 2 minutos levando consigo o material disposto.

\section{Beber água no copo.}

Esse comportamento foi definido como beber água no copo de plástico quando sentisse sede.

\section{Linha de base I e linha de base II.}

A pesquisadora, após aproximar-se da participante no quarto, instruía a mesma a beber água no copo (mostrava-lhe o copo e informava que ia deixar perto da torneira do seu toalete). Quando fosse necessário, a participante tinha que pegar o copo enchê-lo de água e beber. Se ela atendesse ou não a sugestão de beber água no copo, sua resposta era anotada na folha de registro.

\section{Intervenção I e intervenção II: Reforçamento social e extinção.}

Tanto para as Intervenções I como para as Intervenções II as instruções foram as mesmas. A pesquisadora fornecia o copo de plástico pedindo para a participante beber água no copo quando sentisse necessidade. Se a participante tocasse no copo esse comportamento era reforçado com atenção social. Qualquer outro comportamento emitido era ignorado.

\section{Bater palmas.}

Este comportamento consistia em ensinar à participante, meios apropriados de interagir socialmente, batendo palmas em condições sob as quais, estes comportamentos poderiam obter algum tipo de atenção da equipe de recreação ou mesmo de outros pacientes em relação a ela. A participante sentada numa cadeira no centro de recreação estendia os braços para frente num ângulo de $90^{\circ}$ e batia palmas no ritmo da música durante a dança, participando assim dos ritmos das atividades propostas pela equipe de recreação.

\section{Linha de base I e linha de base II.}

A pesquisadora convidava a participante a se aproximar do grupo de internos que se reuniam no centro de recreação no pátio, quando estavam escutando música ou dançando. Em seguida, solicitava a participante para bater palmas no ritmo da música. Cada palma emitida era anotada na Folha de Registro. Independente de a participante bater ou não bater palmas, não havia reforço.

\section{Intervenção I e intervenção I: Reforçamento social.}

A pesquisadora pedia à participante para bater palmas ao se aproximar do grupo de internos na atividade de dança. Qualquer comportamento da participante que se aproximasse da solicitação requerida era imediatamente reforçado. Foi registrado o número de palmas batidas pela participante na folha de registro. Os reforçadores utilizados na atividade de bater palmas foram os reforçadores sociais.

Acordo entre observadores. Durante a fase de coleta dos dados, contou-se com a colaboração de um profissional com experiência em observação para que fosse realizado o teste de concordância dos dados obtidos. Para cálculo do índice foi utilizada a fórmula padrão: [Concordância / (Discordância + Concordância)] x 100. O percentual de fidedignidade foi calculado para cada comportamento e alcançou um alto índice de concordância ainda que com variações (de 89\% a 100\%).

\section{Resultados}

Os resultados obtidos são apresentados em forma de frequência (Figura 1) para os comportamentos: manter contato olho a olho, dar tapas, empurrar e fazer ameaças, beber água no copo e bater palmas ao ritmo de uma música; e intervalos de tempo (Figura 2) para os comportamentos: ficar sozinha, sem atenção; recusar-se a participar das tarefas ou atividades e executar uma atividade durante o tempo livre.

Verifica-se na Figura 1, que os comportamentos de manter contato olho a olho não ocorreram nos intervalos das sessões de linha de base I e II. Em relação à ocorrência do comportamento nas sessões das fases de intervenção I e II, os dados indicam que esse comportamento aumentou em suas frequências e se manteve nas sessões do follow-up.

A frequência do comportamento da participante de agredir as pessoas: dar tapas, empurrar e fazer ameaças na fase de linha de base I e II variou em suas ocorrências. Nas sessões das fases de intervenção I e II e no follow-up pode ser constatada a diminuição da ocorrência do comportamento de agredir da participante. 


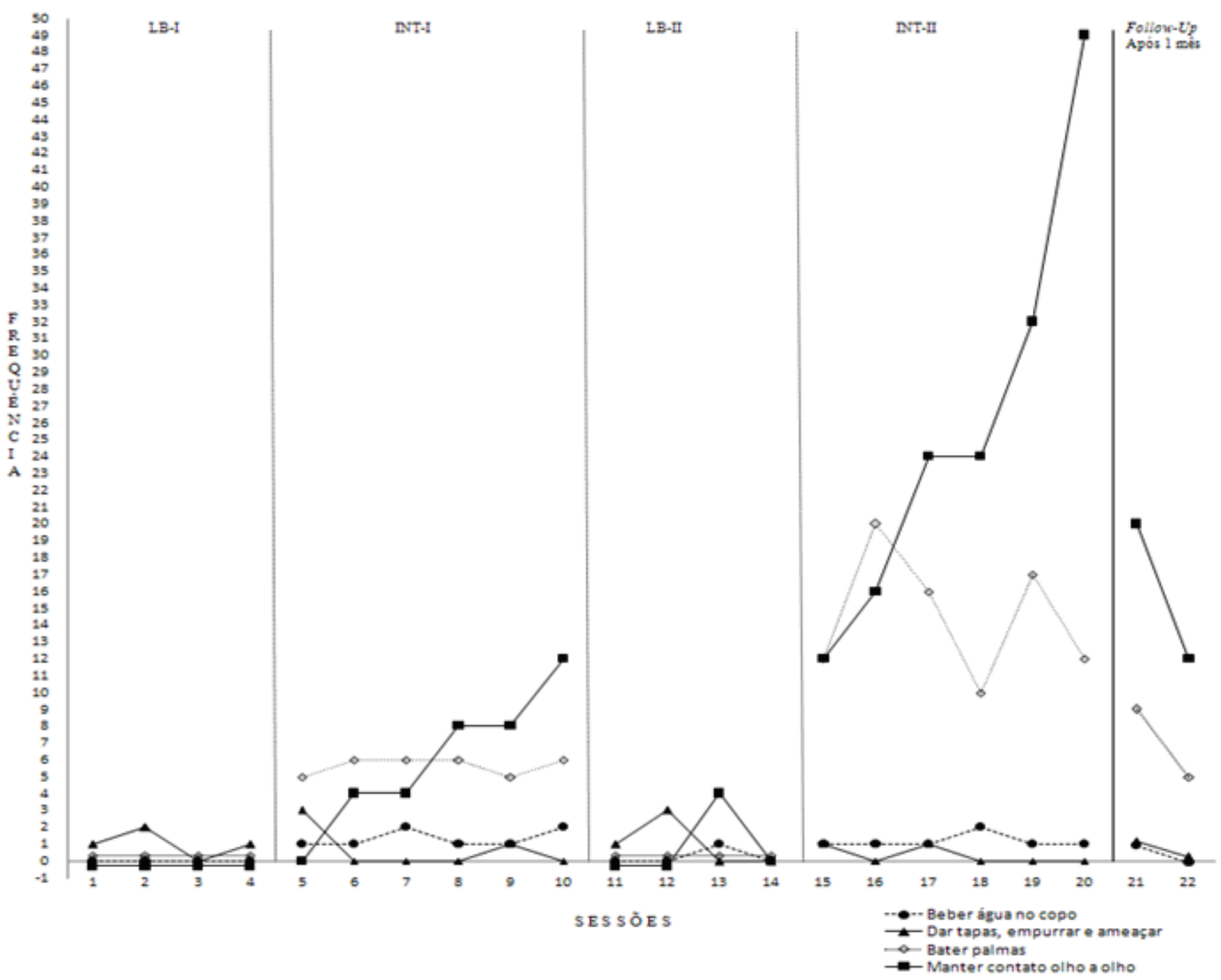

Figura 1. Apresenta as frequencias dos comportamentos de beber água no copo, dar tapas, empurar ou ameaçar as pessoas, bater palmas e manter contato olho a olho de uma participante com o diagnóstico de esquizofrenia crônica e retardo mental.

Para o comportamento de beber água no copo de plástico, observa-se nas linhas de base I e II que a frequência do comportamento foi zero em quase todas as sessões. Os dados revelam uma oscilação da frequência do comportamento de beber água no copo de plástico durante as sessões de Intervenções I e II.

Para o comportamento bater palmas ao ritmo de uma música, a participante não se comportou, obtendo zero ocorrência na linha de base I e oscilou na linha de base II. Nas fases de intervenção I e II, esse comportamento ocorreu em todas as sessões alcançando alta taxa de frequência. Porém, nas sessões de follow-up os dados revelam uma diminuição da frequência do comportamento.

Nas sessões da fase de LB-I e II o comportamento de permanecer sozinha sentada num banco do pátio e sem atenção ocorreu praticamente em todos os intervalos.

$\mathrm{Na}$ fase de intervenção I a frequência de intervalos na primeira sessão para o comportamento de permanecer só foi 108. Diminui para 48 na segunda sessão. Chama atenção que nas terceiras sessões das Intervenções I e II a frequên- cia dos intervalos diminuiu notadamente, alcançando zero ocorrência. Após um período de 30 dias deu-se início às sessões da fase follow-up. Os dados da Figura 2 revelam uma diminuição na frequência do comportamento de se manter sozinha sem atenção nos intervalos de tempo nas duas sessões daquela fase.

Em relação ao comportamento de recusar-se a participar das tarefas ou atividades programadas na Instituição, os dados apresentados na Figura 2 indicam as frequências dos intervalos dessa classe de respostas. Durante as sessões de linha de base I o comportamento da participante em manter-se distante do grupo e não se orientar para execução das atividades alcançou 120 intervalos, indicando a ausência de interações da participante para as atividades orientadas para seus pares.

Os dados indicam certa regularidade nas frequências dos intervalos daquela classe de respostas. No início dos trabalhos a participante recusava-se participar de qualquer que fosse a atividade. No entanto, sob as ações dos reforçadores podem-se observar notáveis mudanças no comportamento da 


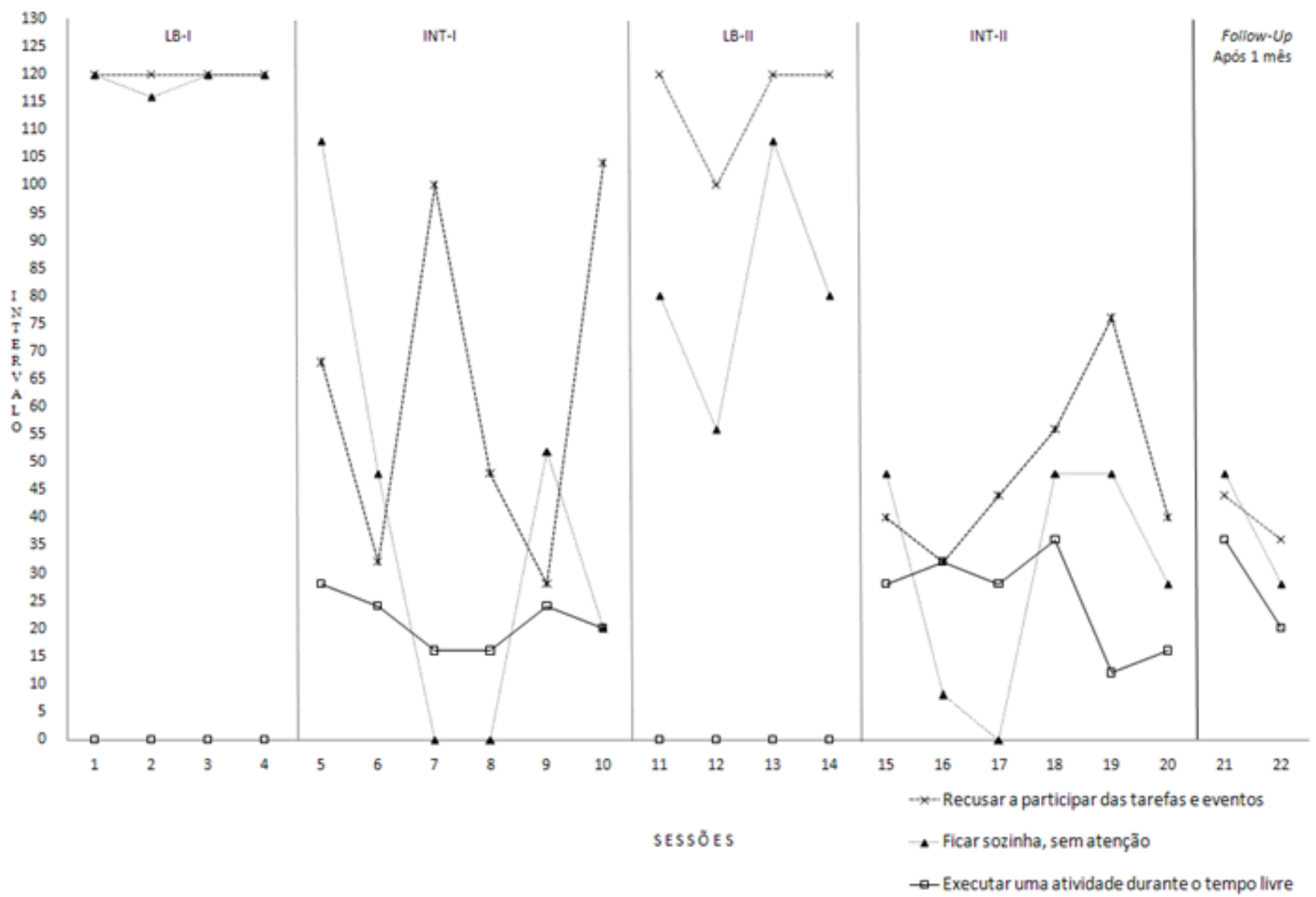

Figura 2. Apresenta as frequências dos intervalos de tempo dos comportamentos de recusar em participar das atividades, ficar sozinha sem atenção e executar uma atividade durante o tempo livre de uma participante com o diagnóstico de esquizofrenia crônica e retardo mental.

participante: de recusa para aceitar e participar nas atividades programadas.

Após um período de 30 dias deu-se início as sessões da fase follow-up, no qual revelam que a recusa da participante para as atividades diminuíram de 44 para 36 intervalos daquela classe de resposta, ou seja, o comportamento de participar das tarefas aumentou em suas ocorrências.

Os dados apresentados na Figura 2 referem-se às classes de respostas em relação ao executar uma tarefa de desenhar, qualquer que fosse o desenho. Nas quatro sessões das fases de linha de base I e II o comportamento da participante em realizar esta atividade selecionada teve frequência zero. Já nas duas fases das intervenções I e II as frequências desse comportamento variaram e alcançaram num total de $152 \mathrm{mi}-$ nutos de realização da tarefa de desenhar quando sequenciada pelos reforçadores. Após um período de 30 dias deu-se início as sessões da fase follow-up, revelando uma diminuição de intervalo de tempo de 36 para 20 nas duas sessões.

\section{Discussão}

O presente estudo teve como objetivo investigar o comportamento de uma pessoa com o diagnóstico de esquizofrenia crônica e retardo mental em uma instituição de saúde mental, particular e conveniada com o SUS. O programa de intervenção visou instalar comportamentos desejados no repertório comportamental da participante e diminuir os comportamentos indesejados. Ambas as classes comportamentais tinha por finalidade facilitar a interação da participante no seu ambiente social.

Para essa finalidade foram aplicados os princípios básicos da análise do comportamento a partir da condução de uma avaliação funcional. Por meio de entrevistas com membros da equipe de enfermagem e de observações diretas foi possível observar que a participante apresentavas vários déficits comportamentais: permanecia sentada num banco do pátio longe dos demais internos, recusava-se a participar de tarefas ou eventos, desviava o olhar das pessoas, etc. Também, excessos comportamentais como agressão física (tapas, empurrões) ou verbal (ameaças) as pessoas. Essas classes comportamentais eram mantidas por reforçamento negativo. A função era fugir das pessoas, das tarefas ou pedidos e de atividades sociais.

A partir dos dados obtidos pelas entrevistas e observações diretas foram selecionadas sete classes comportamentais para sofrer intervenção controlada pelo delineamento de reversão-replicação, seguido por follow-up. O programa de intervenção visava uma melhor adequação da participante ao seu ambiente institucional. Os resultados encontrados comprovam a relevância da modelagem, do reforço positivo 
e da extinção na modificação dos comportamentos-problemas que sofreram intervenção.

Esses resultados corroboram a eficácia da intervenção comportamental para modificar comportamentos de pessoas com o diagnóstico de esquizofrenia (Ayllon \& Michael 1964; Ayllon \& Azrin, 1968; Britto \& cols., 2006; Isaacs \& cols., 1964). Déficits comportamentais como, por exemplo, participar de atividades ou eventos foi avaliado e fortalecido pelo reforçamento positivo. Em relação aos reforçadores sociais foi possível observar na fase de intervenção II, efeitos ainda mais positivos. Já os excessos comportamentais mantidos pelo reforçamento negativo como agressão física e verbal foram enfraquecidos ou extintos: a resposta de agressão que levava à remoção da tarefa deixou de ocorrer.

O desafio imposto foi o de estudar padrões específicos de comportamentos-problema, inclusive os mais severos como os apresentados por pessoas com o diagnóstico de esquizofrenia. $\mathrm{O}$ efeito intrusivo da filmadora no ambiente institucional, principalmente no pátio chamava a atenção das pessoas, impondo algumas dificuldades quando da realização dos registros. Vários momentos foram registrados e descartados até que as pessoas começassem a ignorar sua presença.

Em suma, o presente estudo utilizou das estratégias comportamentais para investigar o comportamento de uma participante em uma instituição de saúde mental. Isso porque as intervenções comportamentais têm sido usadas frequentemente para abordar comportamentos que possuem uma etiologia médica (Martin \& Pear, 2007/2009). Enfatiza-se a importância e justifica-se a sua relevância por ter sido aplicado um programa experimental para estudar o comportamento de uma pessoa com dois diagnósticos: esquizofrenia e retardo mental.

Tradicionalmente, o tratamento prescrito para pessoas com o diagnóstico de esquizofrenia é baseado em causas inferidas a partir de relatos do paciente e observação dos seus comportamentos descritos como 'sintomas' de atividades mentais. Contudo, C. Bernard (1865/1927), considerado o pai da medicina, sugeriu a alternativa "(...) a análise experimental é o nosso único meio de buscar a verdade." (p. 5). Por essa perspectiva, Iwata e Dozier (2008) declaram que ao incorporar procedimentos experimentais na prática clínica, a análise do comportamento está em condições de oferecer uma forte contribuição à avaliação e tratamento dos 'transtornos mentais'.

\section{Referências}

Associação Americana de Psiquiatria (2002). Manual diagnóstico e estatístico de transtornos mentais - DSM-IV-TR (C. Dornelles, Trad.). $4^{\mathrm{a}}$ Edição. Porto Alegre: Artes Médicas (Trabalho original publicado em 2000).

Ayllon, T., \& Haughton, E. (1964). Modification of symptomatic verbal behavior of mental patientes. Behavior Research Therapy, 2, 87-97.

Ayllon, T., \& Michael, J. (1964). The psychiatry nurse as a behavioral engineer. In A. W. Staats (Ed.), Human Learning. Studies extending conditioning principles to complex behavior (pp. 445-457). New York: Holt, Rinehart and Winton, Inc.
Ayllon, T., \& Azrin, N. (1968). The token economy. New York: Appleton Century Crofts.

Bernard, C. (1927). An introduction to the study of experimental medicine (H. C. Greene, Trad.). New York: Macmillan (Trabalho original publicado em 1865).

Britto, I. A. G. S. (2004). Sobre delírios e alucinações. Revista Brasileira de Terapia Comportamental e Cognitiva, 6(1), 61-71.

Britto, I. A. G. S., Rodrigues, M. C., A; Santos, D. C. O., \& Ribeiro, M. A. (2006). Reforçamento diferencial de comportamentos verbais alternativos de um esquizofrênico. Revista Brasileira de Terapia Comportamental e Cognitiva, 8(1), 73-84.

Britto, I. A. G. S., Rodrigues, I. S., Alves, S. L., \& Quinta, T. L. S. (2010). Análise funcional de comportamentos verbais inapropriados de um esquizofrênico. Psicologia: Teoria $e$ Pesquisa, 26, 139-144.

Burns, C. E. S., Heiby, E. M., \& Tharp, R. G. (1983). A verbal behavior analysis of auditory hallucinations. The Behavior Analyst, 6(2), 133-143.

DeLeon, I. G., Arnold, K. L., Rodriguez-Carter, V., \& Uy, M. L. (2003). Covariation between bizarre and nonbizarre speech as a functional of the content of verbal attention. Journal of Applied Behavior Analysis, 36(1), 101-104.

Dixon, M. R., Benedict, H., \& Larson, T. (2001). Functional analysis and treatment of inappropriate verbal behavior. Journal of Applied Behavior Analysis, 34(3), 361-367.

Isaacs, W., Thomas, J., \& Goldiamond, I. (1964). Application of operant conditioning to reinstate verbal behavior in psychotics. In A. W. Staats (Ed). Human Learning: Studies extending conditioning principles to complex behavior (pp. 466-471). New York: Holt, Rinehart and Winton, Inc.

Iwata, B. A., \& Dozier, C. L. (2008). Clinical application of functional analysis methodology. Behavior Analysis in Practice, 1, 3-9.

Lancaster, B. M., Le Blanc, A., Carr, J. E., Brenske, S., Peet, M. M., \& Culver, S. J. (2004). Functional analysis and treatment of the bizarre speech of dually diagnosed adults. Journal of Applied Behavior Analysis, 37(3), 395-399.

Marcon, R. M. (2010). O comportamento verbal do esquizofrênico sob múltiplas condições de controle. Dissertação de mestrado, Pontifícia Universidade Católica de Goiás, Goiânia.

Martin, G., \& Pear, J. (2009). Modificação de comportamento: O

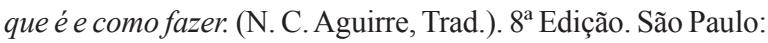
Roca (Trabalho original publicado em 2007).

O’Neil, R. E., Horner, R. H., Albin, R. W., Sprague, J. R., Storey, K., \& Newton, J. S. (1997). Functional assessment and program development for problem behavior: A practical handbook. Pacific Grove: Brooks/Cole.

Reese, H. (1978). Análise de comportamento humano (G. P. Wintter, Trad.). Rio de Janeiro: José Olympio (Trabalho original publicado em 1966).

Rutherford, A. (2003). Skinner boxes for psychotics: operant conditioning at Metropolitan State Hospital. The Behavior Analyst, 26(2), 267-279.

Santana, L. A. M. (2008). Comportamento verbal e esquizofrenia: estratégias operantes de intervenção. Dissertação de mestrado, Pontifícia Universidade Católica de Goiás, Goiânia. 
Sidman, M. (2005). A análise do comportamento humano em contexto. Revista Brasileira de Análise do Comportamento, 1(2), 125-133. Publicação simultânea no The Behavior Analysts, 27(2), 189-195.

Staats, A. W., \& Staats, C. K. (1973). Comportamento humano complexo (C. M. Bori, Trad.). São Paulo: EPU (Trabalho original publicado em 1963).

Staats, A. W. (1996). Behavior and personality: Psychological behaviorism. New York: Springer Publishing Company Inc.

Skinner, B. F. (1970). Ciência e comportamento humano (J. C Todorov \& R. Azzi, Trad.). Brasília: UnB e FUNBEC (Trabalho original publicado em 1953).

Skinner, B. F. (1969). Contingencies of reinforcement: a theorical analysis. New York: Appleton Century Crofts.

Skinner, B. F. (1973/1979). O que é comportamento psicótico? In T. Millon (Ed.), Teorias da Psicopatologia e Personalidade (E. D. V. Vianna, E. Nick, L. Peotta \& M G. R. Maron, Trad.). (pp.188-196). Rio de Janeiro: Interamericana (Trabalho original publicado em 1973).
Vollmer, T. R., Borrero, J. C., Wright, C. S., Camp, C. V., \& Lalli, J. S. (2001). Identifying possible contingencies during descriptive analyses of severe behavior disorders. Journal of Applied Behavior Analysis, 34(3), 269-287.

Wilder, D. A., Masuda, A., O’Connor, C., \& Bahan, M. (2001). Brief functional analysis and treatment of bizarre vocalizations in adult with of schizophrenics. Journal of Applied Behavior Analysis, 34(1), 65-68.
Recebido em 15.09.2009

Primeira decisão editorial em 19.07.2010

Versão final em 16.08.2010

Aceito em 26.08.2010 